\title{
Women, employment and the family: report on a colloquium comparing the women's movement and government legislation for gender equality in Britain and Vietnam
}

\author{
Christine Pelzer White
}

In March 1983, a colloquium on Women, employment and the family was jointly organised by the Social Sciences Research Commission(SSRC, Hanoi, Vietnam) and the Institute of Development Studies (IDS, Sussex, UK), with financial support from the Swedish International Development Authority.

The main aim of the colloquium was to compare state policy and legislation on women's employment and the family in Britain and Vietnam. This might at first seem an unlikely enterprise. The economic and political contexts of the two countries are fundamentally different: Vietnam is a mainly agricultural socialist country; Britain an industrialised capitalist nation. However, while the importance of these differences should not be minimised, there are a number of underlying similarities which make the comparison both richer and more complex than might be initially expected. The first of these stems from the universality of the phenomenon of the subordination of women, the second lies in certain common aspects of the development process. Let us take these two in turn.

In no country in the world are men and women social equals. It is the common aim of women's movements throughout the world - North and South, East and West - to liberate women and advance toward full equality between men and women. In both Britain and Vietnam there are women's organisations devoted to this struggle.

Governments in both countries have brought in legislation specifically aimed at promoting women's equal rights in employment and within the family. Such legislation can be found in both capitalist and socialist countries, whereas in pre-capitalist and pre-socialist societies relations between employers and employees, and between family members are determined by the balance of economic power and elaborate customary traditions.

As societies become more industrialised and their occupational structures become more complex (the history of Western industrialised nations and the universal developmental aim of Third World governments), the social relations of work and family are increasingly subject to government legislation. Although governments are more reluctant to intervene in the 'private' sphere of gender and familial relations, all governments do exercise varying degrees of legislative influence in these spheres. This may have the aim of preventing change in the economic system from transforming 'traditional' gender relations and patterns of women's subordination (for example, the Iranian Government of Ayatolla Khomeini), or of transforming traditional gender and family relations in accordance with new social norms, such as equality (whether this be defined in liberal or socialist terms). A widespread example of this is legislation outlawing child and arranged marriages, polygamy and bride price payments in favour of monogamous free-choice marriage after a legal minimum age. Such legislation is the norm in both industrialised and socialist countries. One of the aims of the overseas participants in the colloquium was to familiarise Vietnamese researchers with feminist discussions in Britain on the implications for women of the past decades of often seemingly 'progressive' social welfare measures and government regulations affecting work and marriage. The results have often entailed subtle forms of women's subordination.

Policies, legislation and employment trends which date back over 50 years in Britain, such as protective legislation excluding women from night work and certain types of heavy work, and the feminisation of professions considered particularly suitable for women (eg, school teaching and nursing) are presently under consideration or emerging in Vietnam.

More generally, the ubiquitous social allocation of primary responsibility for childcare and housework to women gives working women extra burdens, favours male professional advancement, and means that women in all countries undergoing industrialisation and professionalisation face certain common problems. 


\section{Report on the Colloquium}

There were 25 regular participants at the colloquium with another 10 to 15 people attending one or more sessions. The overseas speakers were Kate Young and Christine White from the Institute of Development Studies at the University of Sussex and Sheila Smith, an economist from the University of Sussex. Birgitta Sevefjord of the Swedish Embassy in Hanoi attended as SIDA rapporteur. The Vietnamese participants, convened by Le Thi, Vice Director of the Philosophy Institute, came from institutes of the Social Sciences Research Commission and from research sections of the Women's Union, the Ministry of Labour, the Trade Union Federation, and the Committee for the Protection of Mothers and Children.

The composition of the Vietnamese participation in the colloquium was influenced by the fact that much policy related research is carried out in ministries and other specialised agencies, rather than in research institutes. The Women's Union works directly with women in grass roots policy implementation, but has few organisers with the training necessary for research. The SSRC, Women's Union and ministries have cooperated in research and discussion of policy issues. Bao Kim, Vice Director of the Social Sciences Information Institute of the SSRC, in charge of the documentation and bibliographic section, introduced the situation of Vietnamese women researchers in the SSRC. One half of the research staff are women. Of these 200 women researchers, about 10 per cent are senior staff with major publications, another one-third are between 30 and 40 years of age with some research and publication experience, and the remainder are recent university graduates who are combining postgraduate studies with their work. Institutes in which women researchers have played a significant role include: Philosophy, Modern and Classical Literature, Ethnography, Archæology, History, Linguistics, Law, Economics, and South East Asian Studies.

A total of 18 papers were presented at the colloquium with texts available in two languages (English and Vietnamese). These covered key women's issues with particular focus on research and policy discussion in Vietnam for the preparation of new legislation on state sector employment and on a new marriage law (in Vietnam), and on feminist research in Britain on the issues of women's employment and the family.

As information on the situation in Britain is quite readily available, this set of presentations will only be briefly summarised here. The papers on Britain introduced key policy, organisational and analytical issues concerning women's situation in employment and the family. The policy-related topics presented included the current debate on family policy, government and trade union policy on child care and maternity provisions, equal pay and labour protection legislation and the rise of battered wives' centres. Analytical papers discussed the feminist critique of conventional economic categories, the interconnectedness of women's work in the labour force and the home, and the new priority given to the academic study of previously neglected women's concerns such as housework and maternity. Organisational and political issues, including the autonomous nature of the women's movement in Britain, the Greenham Common Women's Peace Movement and the impact of feminist issues on the British Communist Party were also discussed. A collection of background documentation covering all of these topics, including books and articles, was provided to the SSRC. The Vietnamese Women's Union requested that the Social Sciences Information Institute provide them with translations and summaries of this material, and the wealth of information made available prompted the Vietnamese participants to request further that the Social Sciences Research Commission set up a Scientific Research and Information Centre to house such international documentation and promote cooperation between Vietnamese researchers and their foreign colleagues.

The Vietnamese contributions began with an overview paper, 'On the movement for women's emancipation in Vietnam' by Le Thi, the vice-director of the Philosophy Institute, who had convened the Vietnamese participants. She argued that the achievement of gender equality involved two related processes: first, the complete abolition of economic exploitation and class divisions in society and, second, the abolition of all aspects of specifically sexual inequality. These two factors would establish equal opportunity for educational and occupational advancement. Major legislative steps had been taken in Vietnam to guarantee women's rights: equal rights were written in to the state constitution in regard to all social and political activities, equal pay, rights to maternity leave and creches. Women had made considerable progress over the past three decades: for example, 42.2 per cent of all government workers were women, 31 per cent of technical and scientific workers with advanced education and 50 per cent of students in secondary vocational training. But legislation could not solve the problem of women's liberation automatically, and the very progress of women's advancement had brought a crop of new problems which required special attention from policymakers (problems with child-care, transportation, professional training, health, housing, access to leadership positions) - problems which are particularly pressing in the cities. New policies were required (and old policies needed to be implemented) to improve women's status as citizens, as workers and as mothers, and to improve the working conditions, educational 
opportunities and personal life of all women. Effective implementation of positive policies was being hindered by economic constraints and conservative attitudes and the question of improving women's position could not be separated from the broader process of the 'three revolutions': in relations of production, in science and technology and in ideology and culture.

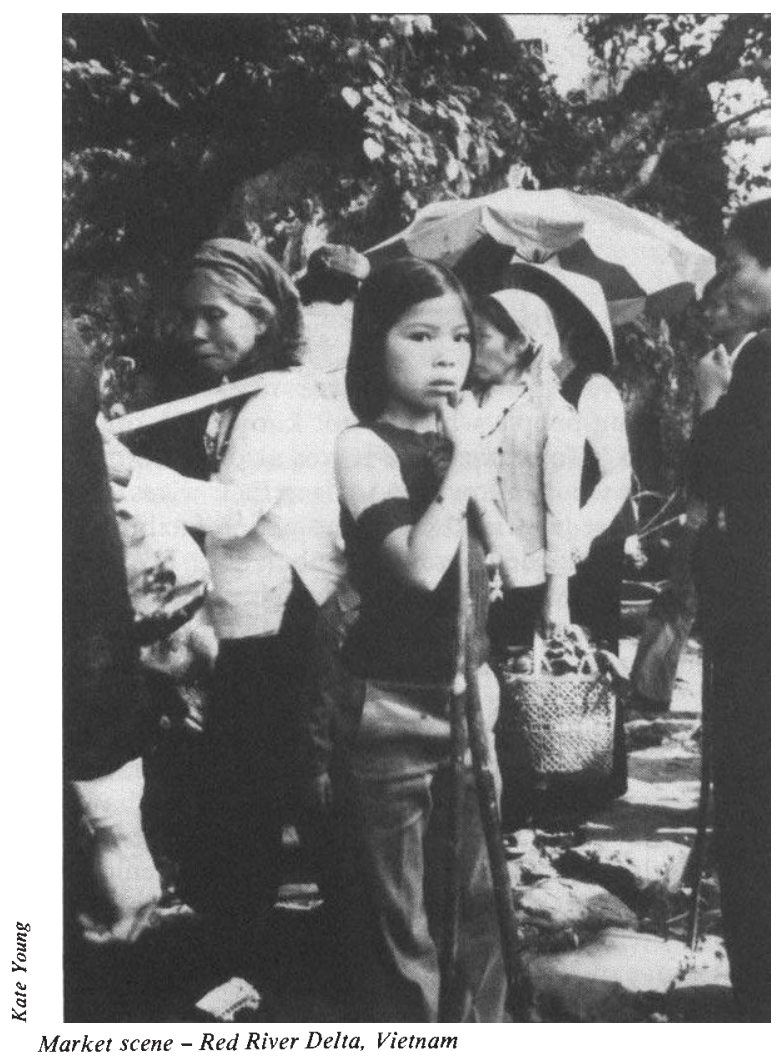

Tran thi Hong Diem of the Women's Union and the deputy head of the Women's Union drafting committee for the new marriage law presented a paper entitled, 'Some general features of marriage and the family in Vietnam'. Traditional or feudal Vietnamese marriage had included parental control and choice of partners, child marriage and polygamy. The marriage law of 1959 had established the basic principles of 'one man one wife' and free choice marriage. Although there are still some cases of forced marriage, this earlier law was basically implemented. However, the scope of socioeconomic and cultural change over the past 20 years necessitates a new marriage law. Within the guidelines of the principles of the existing law, it is intended that the new law will contain more specific provisions concerning the financial responsibilities of parents after divorce as well as dealing with the relatively new phenomenon of marriage between Vietnamese and foreigners. To prepare the new law a number of studies have been carried out on such questions as the age at marriage, the reasons for divorce, family decision-making in major purchases, etc. In general, the principal reason leading to divorce is conflict and disagreement between husband and wife. Whereas in the countryside the root of this disagreement often lies in conflict between the husband's parents and the daughter-in-law, in the cities the main problem is disagreement between husband and wife over the family budget. The problem of over hasty marriage between urban young people was raised; in some areas of Hanoi the divorce rate is as high as 10 per cent, with a trend in recent years for most divorces to occur after only three to five years of marriage.

A paper entitled, 'Policies on women's labour' was presented by Phuong Tao, formerly with the Federation of Trade Unions, and now head of the Women's Union research team on labour legislation. She stressed that the right to work is the key to women's equality; equal rights in the family would come from economic independence and equal earnings. She argued that implementing the principle of equality between men and women is not just a task for women but a duty of the party, the state and society as a whole. It is a matter of principle that there should be no discrimination between men and women in the workplace in terms of rights and remuneration. The socialist revolution has benefited women through policies enabling them both to perform their role as mothers and to participate in social production. Major achievements have included a massive increase in the participation of women workers in the state and collective sectors, a change in the distribution of women workers towards more suitable jobs, and improvement in the skills and capacities of women workers, equal pay for equal work, and, in the state sector, special treatment for women during menstruation and pregnancy, paid maternity leave, and the right to paid leave to look after sick children of up to seven years. Many cooperatives are also introducing these measures. Outstanding problems are largely because of legacies of the past and the low level of development of the productive forces.

'Progress in the process of building socialism of women of ethnic minorities in Vietnam' by Tu thi Cung (pen name $\mathrm{Ha}$ Chau) of the Institute of Ethnology described some of the achievements in bettering living conditions in the mountainous regions. There are 54 different ethnic groups, varying widely in economic situation, but the government has striven to develop their productive capacity and 
eliminate backward customs. Particular care has been given to educating both men and women cadres from the minorities. She noted that for particularly small ethnic groups the government was not trying to limit their population growth.

Do thi Kim Quy of the Federation of Trade Unions presented a paper on 'Women staff and women workers in Vietnam' which described the position of women civil servants, their progress and achievements, the policies of the trade union and the state towards women workers. Policies to promote material incentives were described, as well as the rationed provision of basic commodities at controlled prices, and the use of the social insurance and social welfare funds. The activities of the factory level Women's Affairs Committees were also discussed.

Dr Vu thi Chin of the Committee for the Protection of Mothers and Children presented a paper on 'The problem of women staff and women workers' childbirth and labour productivity'. This concentrated on the problems arising because the prime working age corresponds to women's childbearing and caring years. Two issues were discussed in detail: measures to promote birth control, and the provision of creches and maternity leave. She argued that birth control is vital to limit the growth of the population and the size of each family, and noted the government's promotion of the two or three child family through prize incentives. She argued that the provision of maternity leave needs to be lengthened from two to three months (although the present reform only lengthens it from two to two and a half months). She stressed both the medical and economic advantages of breast feeding over reliance on expensive and imported cows' milk which neither the state nor individual families can afford in sufficient quantities. While in theory creches near the place of work should make it possible for women to continue breast feeding after the end of the existing two months of maternity leave, her research has shown that in fact women generally, whether working in factories, state farms or offices, do not continue breast feeding after returning to work. This is why the Committee for the Protection of Mothers and Children has recommended extending maternity leave to three months.

The paper by Le thi Nham Tuyet of the Institute of Ethnography on 'Traditions and their impact on the study of women in Vietnam' stressed the need for research on existing practices and customs to form the basis for government policy. For example, provisions exist for Vietnamese women to take one month of maternity leave before childbirth. However, traditionally Vietnamese women worked up until childbirth and they had continued to do so, ignoring the maternity leave provisions, because of the fear that otherwise the baby will be too big and they will have a difficult birth. A number of other recent government programmes, such as family planning, have faced the obstacle of deep-seated opposing traditions. Unless policies are based on research and understanding of existing practices and customs they are not likely to be effective.

\section{Roundtable Discussions}

Discussions centred on four major topics: marriage and the family, work, the relationship between the family and labour force participation, and training for women.

As regards marriage and the family, the main concern expressed by the Vietnamese researchers was how to ensure family harmony and stability. While unhappiness and a persistent desire for divorce on one side is clearly no basis for continuing a marriage when reconciliation attempts fail, great concern was expressed over the rising divorce rate, especially among young people who did not know each other well enough before marriage. It was also feared that easy divorce would allow men to drop their wives and marry younger girlfriends, a phenomenon facilitated by the post-war demographic imbalance. Because women generally earn less than their husbands, and the children stay with the mother, divorce creates economic hardship for women.

The demographic imbalance resulting from years of war creates severe problems for women. While it is the cultural norm that all women should marry and have children, there are not enough men; this problem is particularly severe for women working on remote state farms (such as tea growing farms) with a primarily female labour force. Many of these women past the age of 30 (after which it is very difficult for a Vietnamese woman to marry) want to have a child to take care of and to care for them in their old age, but have no husband. The choice by several such young women to be unwed mothers was recently raised in the press. On the one hand it is important to respect their right to have children, not to force them to have abortions or deny their children rations. However, both wives and the Women's Union are afraid that a more liberal view of extramarital sexual relations and unwed mothers will undermine the very recently established principle that men should not have more than one wife. The traditional cultural pattern of "main wife' and 'little wife' could recur.

The change in residential family type from extended to nuclear and its effects on the distribution of work in the family was discussed. Although there is need for a reduction in population growth and family size, there is resistance to birth control, especially from men and from older women wanting many grandchildren. 


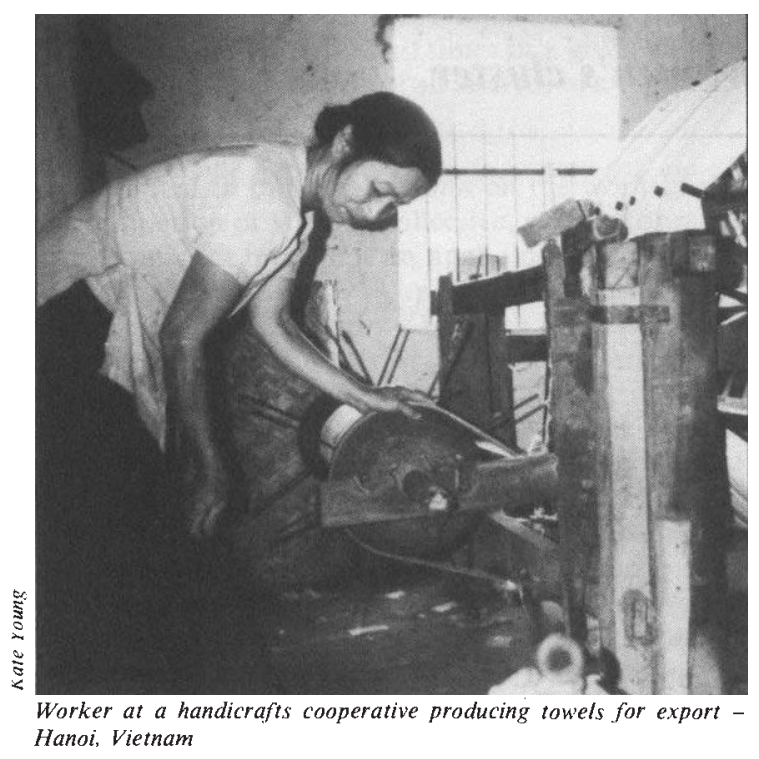

The British researchers stressed the unequal division of work including caring and servicing activities within the family and the effect of this on the time women have available for educational, training, cultural and political pursuits. They drew attention to the unequal power relations within the family, especially between men and women, and the widespread social effects this has, the most severe but not isolated - manifestation of this being wifebattering. They emphasised the need to redistribute 'family work' equally between men and women of all generations.

\section{Work}

The Vietnamese participants stressed that whereas the state has many good policies concerning women's labour force participation, the present problem is how to implement them well, while at the same time there is need for amendments and clarification of a number of points to make the policies more appropriate to present conditions. Because the level of science and technology in Vietnam is still low, many women must do heavy manual labour in agriculture, road construction, dock work and in industry. It is necessary to pay attention to protecting the health of women workers, especially when pregnant and caring for young children, and to lessen women's heavy labour and improve working conditions. One set of proposals under discussion involved making some categories of extremely heavy work closed to women, while promoting women's professional training in skilled, lighter and more appropriate work (eg, education, medical care, handicraft production). The problems of maternity leave, night shift work, the illogicalities of the pay scale system (now over 20 years old) and the difficulties women workers face in getting in-job skill training and further education were discussed at length.

The British participants emphasised the dangers of sex-stereotyping of jobs, the way in which 'skill' is defined, how jobs are graded and rates of pay calculated, and questioned the relationship between a long working day and high output. The experience of the women's movement in England is that even quite skilled professions (eg, nursing) are low paid once they are socially categorised as 'women's work'. The fact that women provide free work and care in the home seems to lead to the monetary devaluation of their work for society as well.

\section{The Relationship between Family and Employment}

The contradiction between the need for labour of the family-based subcontracting (khoan) system in cooperative agriculture and the family planning policy was noted. The main subject of concern for the Vietnamese participants was the acute contradiction between the physical demands of pregnancy, childbirth and breast feeding on the one hand, and women's role in the work force and productivity on the other. The need to develop appropriate policies to solve this severe problem was discussed. The British participants stressed the many ways in which men and women's different roles in the family structured their labour force participation, promotion and pay, and argued that although, clearly, childbearing and breastfeeding are biologically determined, most aspects of the sexual division of labour both in the family and in society are structured by culture, social opinion and social policy rather than by nature.

\section{Training}

The difficulty which Vietnamese women have in getting the same level of training as men was discussed at length. The ability of a wife and mother to take advantage of existing training and educational opportunities depends not only on social services (in Vietnam these include creches, the sale of food at place of work to save the time spent in queues, etc), but also, in Vietnam as in England, on the kindness and helpfulness of husbands and other family members. The need for better training (in quality and quantity) for women was stressed, including the need to facilitate women's overseas training if needed for their field of work.

\section{Results}

Following the colloquium, a Women's Research Unit was established in the Social Sciences Research Commission, Hanoi. This new unit is chaired by Le Thi who had played a major role in organising the Vietnamese colloquium participation. The Unit is now drawing up its work programme and is interested in contact and documentation from institutions in the field of women's research. 